\title{
CONSULTA DE ENFERMAGEM A CLIENTE HIPERTENSO: ANÄLISE DE UM INSTRUMENTO UTILIZADO E PROPOSTA DE UM NOVO MODELO *
}

\author{
Leda Maria Doccosse Pavani** \\ Luci Maria Ferreira** \\ Hsia Sac Wah** \\ Suely Sueko Viski Zanei***
}

PAVANI, L.M.D.; FERREIRA, L.M.; WAH, H.S.; ZANEI, S.S.V. Consulta de enfermagem a cliente hipertenso: análise de um instrumento utilizado e proposta de um novo modelo. Rev. Esc. Enf. USP, São Paulo, 22(1):85-102, abr. 1988.

As autoras tecem consideraçōes preliminares sobre Consulta de Enfermagem e analisam o instrumento utilizado na consulta a clientes hipertensos de um hospital especializado em cardiologia. Através desta análise foi constatada a necessidade de adequą̧ão do instrumento para a clientela especifica. Acredita-se que a adequação do instrumento seja importante elemento facilitador para a execuşäo da Consulta de Enfermagem e para melhor direcionamento das ą̧óes pela enfermeira. Após prática vivenciada pelas autoras, foi proposto um modelo que consta de histórico de enfermagem, levantamento de problemas, plano de orientação e de cuidados de enfermagem $e$ folha de evoluşäo. Para que este modelo seja utilizado de modo uniforme, foi elaborado um manual de orientą̧ão.

UNITERMOS: Consulta de enfermagem. Hipertensão arterial.

\section{INTRODUÇÃO}

A hipertensão arterial é uma patologia de alta incidência na população adulta ( 15 a $20 \%$ ), sendo considerada o maior fator de risco para o aparecimento e o agravamento de lesões cardiovasculares e, conseqüentemente, encurtando a expectativa de vida dessa população. 5.i

Trata-se de um problema sério de saúde pública, uma questão dificil, um forte desafio cientifico.

Neste processo, tornam-se necessárias mudanças na direção das ações do enfermeiro, a fim de que o trabalho com o cliente hipertenso reflita sobre a prática profissional. Sabe-se da dificuldade em serem mantidos os niveis tensionais de um hipertenso, quer por razões psicoemocionais, quer pelos efeitos colaterais das drogas antihipertensivas,

- Trabalho realizado no curso de Especializaçăo em Enfermagem em Cardiologia - Modaldade de Resldencla - ERYSP/INCOR, e apresentado no XXXVIII CONGRESSO DE ENFERMAGEM, Rlo de Janelro.

- Enfermelra do Instituto de Coracăo do Hospital das Clínicas da Faculdade de Medicina da USP.

** Enfermelra do INAMPS - Hospital Ipiranga-SP. 
quer pela resistência a mudanças de hábitos de vida, quer pelo custo financeiro do tratamento, o que exige do enfermeiro conduta sistematizada.

Em face da importância do assunto, foi elaborado um programa de atendimento ambulatorial ao cliente hipertenso, no Instituto do Coração (INCOR) da Faculdade de Medicina da Universidade de São Paulo, no qual a Consulta de Enfermagem (C. E.). foi incluída como atividade autônoma e especifica do enfermeiro. Participaram na realizaçāo dessas consultas, enfermeiras do Curso de Especialização em Enfermagem em Cardiologia na Modalidade de residência ( $\mathrm{EC} / \mathrm{R}$ ), bem como as enfermeiras do ambulatório do INCOR.

Para o desenvolvimento da C.E. foi elaborado pelas enfermeiras da Instituição, um instrumento inicial, já tendo por propósito a sua avaliação após período de experimentação.

O presente trabalho tem por objetivo analisar o instrumento utilizado para C.E. ao cliente hipertenso e propor modificaçōes a partir da sua aplicação.

\section{CONSIDERAÇÕES QUJANTO A CONSULTA DE ENFERMAGEM}

A C.E. vem sendo utilizada como uma estratégia de assistência de enfermagem a clientes de diferentes grupos populacionais.

A experiência das autoras na utilização da C.E. no atendimento a grupos de hipertensos permitiu consolidar aspectos já relatados, quanto a sua validade na abordagem de clientes não hospitalizados. $1,2,3,4$

Segundo PIERIN 6 o enfermeiro deve atuar de forma participante junto ao cliente hipertenso, utilizando o papel de educador como forma de abordagem; isto possibilita relacionamento de apoio, com vistas a participação cada vez mais ativa do cliente em seu auto-cuidado, pois somente a partir do momento em que estiver envolvido o suficiente com toda a problemática do "continuum" saúde-doença, é que poderá haver controle satisfatório da pressão arterial.

$\mathbf{E}$ claro que o enfermeiro é quem deve ter a competência de determinar quais as açōes de enfermagem mais apropriadas para o cliente, independentemente de outros profissionais da área de saúde; e a C.E. é uma atividade privativa do enfermeiro.

Não bastam só considerações ou conceitos teóricos sobre a que é C.E.; é prioritário que o enfermeiro, ao realizá-la, esteja consciente do processo que vem aplicando.

$\mathrm{E}$ preciso habilidade e preparo para se impor ao cliente como agente de educação e de ajuda, bem como atitude e segurança profissional.

Para que o enfermeiro alcance a competência profissional esperada, torna-se imprescindivel: 
a) quanto à atuação na C.E:

- ter embasamento científico específico;

- prioritariamente fazer análise global da situação do cliente, a partir da valorização do caráter individual da C.E.;

- procurar obter, tanto quanto possivel, dados que permitam maior conhecimento da realidade do cliente, o que favorece uma ação de enfermagem efetiva e coerente;

- ser capaz de realizar mudanças que favoreçam a saúde do cliente, levando em consideração a influência de fatores como ambiente e suas condições físicas e psicológicas; sional:

b) quanto à busca contínua de conhecimento e crescimento profiscam a C.E.;

- promover intercâmbio com outros profissionais que prati-

- pesquisar o assunto, aplicar os conhecimentos decorrentes dos resultados obtidos e avaliar continuamente o processo; mulos constantes;

- considerar o cliente como uma das fontes geradoras de estí-

- buscar novos conhecimentos que possam ser revertidos em benefícios do próprio cliente.

\section{ANALISE DE UM INSTRUMENTO UTLLIZADO PARA CONSULTA DE ENFERMAGEM}

A realização da C.E. no periodo de $27 / 10$ a $29 / 11$ de 1985 a 27 clientes hipertensos permitiu uma análise preliminar do processo realizado e, principalmente, do instrumento utilizado no INCOR (Anexo I). Essa análise foi dirigida no sentido de adequar o instrumento à C.E. do cliente hipertenso e fundamentada na opiniäo dos enfermeiros que experienciam tal prática.

Apesar do reconhecimento da importância desta análise para o aprimoramento da C.E., acredita-se que a qualidade da mesma deverá refletir-se não somente no impresso empregado como, também, na habilidade do profissional em aplicá-la.

OPINIÃO DOS ENFERMEIROS QUANTO A FORMA, CONTEÜDO E OPERACIONALIZAÇÃO DO INSTRUMENTO UTILIZADO NA C.E.

Os enfermeiros emitiram opiniōes quanto às dificuldades encontradas na utilização do instrumento preconizado, sendo a seguinte a síntese dos resultados: 
- Quanto à forma: não é suficientemente adequada devido aos espaços estreitos, que prejudicam a visualizaçāo;

- Quanto ao conteúdo: não caracteriza o hipertenso pela ausência de itens específicos para avaliação de órgãos alvos e relato de problemas psicossociais;

- Quanto à operacionalização: dificultada, devido aos pontos acima referidos;

- Quanto ao plano assistencial: a maioria concordou que deve ser feito nāo só verbalmente, mas também por escrito, pois os clientes esquecem-se dos conselhos recebidos verbalmente; não só é importante que levem um plano escrito para casa, a fim de discuti-lo com a família, como o plano por escrito é uma forma de registro e um facilitador para o auto-cuidado.

Além disso o plano por escrito é o produto final de todo esse proresso de atendimento, que comprova sua importância tanto para benefício do cliente como para o reconhecimento do profissional.

Ainda, para as autoras, a folha de elenco de problemas a serem resolvidos fica prejudicada em alguns aspectos, não refletindo fielmente a problemática do cliente hipertenso. Isto porque, quando o problema' é transcrito para essa folha, nem sempre é passado na íntegra, tornando-se dissociado do histórico e perdendo as caracteristicas reais nele relatadas.

Este é um dado importante, porque as açōes de enfermagem podem ser menos efetivas. Por outro lado, se for transcrito na integra, torna-se repetitivo e cansativo para o enfermeiro e, consequentemente, há quebra do estímulo para a realização da C.E. como rotina diária.

\section{ADEQUAÇÃO NA UTILIZAÇAOO DO INSTRUMENTO DA C.E. SEGUNDO A NORMA PRECONIZADA}

O instrumento (Anexo I), utilizado para C.E. no ambulatório do UNCOR, inclui 2 itens agrupados em 5 tópicos. a saber:

- identificação do cliente;

- ambiente e hábito; manutençảo da saúde:

- avaliação das funções fisiológicas;

- aspectos psicossociais;

- identificação do entrevistador.

O preenchimento dos itens desse instrumento segue uma norma pré. estabelecida.

Para avaliação do instrumento, foram analisados 27 históricos de enfermagem (H.E.). 
$\mathrm{Na}$ análise foi observado que a maioria dos H.E. foi preenchida de acordo com as normas estabelecidas. Constatou-se também que, em muitos itens, foram investigados dados a mais do que o solicitado, significando que o mesmo precisa ser mais abrangente e específico para o hipertenso.

Considerando-se estes dados, verificou-se que há necessidade de reavaliação das normas e do instrumento, para que estes facilitem a ope: racionalização da C.E., permitindo, com isso, que sejam alcançados os objetivos propostos para a mesma.

\section{PROPOSTA DE UM INSTRUMENTO PARA A CONSULTA DE ENFERMAGEM E MANUAL DE ORIENTAÇAOO}

Em face da análise do instrumento utilizado para C.E. e das normas do programa de hipertensão do INCOR, da fundamentaçāo bibliográfica e da experiência das antoras na C.E., sentiu-se a necessidade de se propor um novo instrumento (Anexo II) e um manual de orientação para o enfermeiro (Apêndice).

O instrumento proposto consta de três impressos com: histórico de enfermagem e levantamento de problemas; folha de evolução de enfermagem; plano de orientação e cuidados de enfermagem.

O manual de orientaçōes para o enfermeiro (Apêndice) inclui: finalidade, considerações básicas quanto à C.E. normas para o preenchimento do instrumento preconizado.

Com esta proposta, espera-se facilitar a atuação do enfermeiro na C.E. e caracterizar o cliente hipertenso, visando a melhoria da qualidade de assistência de enfermagem.

\section{CONSIDERAÇOES FINAIS}

Apesar das dificuldades encontradas, este trabalho foi gratificante na medida em que permitiu estudar e questionar sobre este tema.

A C.E. do hipertenso, como uma atividade em fase inicial no INCOR, vem caminhando de forma concreta e efetiva, sendo o caráter de reavaliaçāo, proposto pela entidade, um fator importantíssimo em todo o processo, por garantir sua qualidade e continuidade.

O preparo e a habilidade do enfermeiro e seu contínuo aperfeiçoamento, tornam-se imprescindiveis na prestação eficiente da assistência com o auxílio da C.E.

Objetivando crescimento continuo do profissional e melhor assistência ao cliente, foi proposta a adequação do instrumento até então utilizado para a C.E.; sugere-se que seja o mesmo submetido a experimentação e subseqüente análise e avaliação de sua utilidade. 
PAVANI, L.M.D.; FERREIRA, L.M.; WAH, H.S.; ZANEI, S.S.V. Nursing consultation of the hypertensive patient: analysis of a current instrument and development of a new model. Rev. Esc. Enf. USP, São Paulo, 22(1):85-102, Apr. 1988.

This is a preliminary study on nursing consultation for hypertensive patients and analysis of the instrument used in a cardiology hospital. The development of an adequate instrument for this kind of patients, with a specif model for assessment, orientation plan, nursing care plan and evolution, was followed by the preparation of an orientation guide to be used by nurses, so an uniformed way of registration could be obtained.

UNITERMS: Nursing consultation. High blood pressure.

\section{REFERENCIAS BIBLIOGRAFICAS}

1. ANDRADE, O.B. Consulta de enfermagem em sistema de programas de saúde. Rev. Bras. Enf., Rlo de Janeiro, 1(1):8-32, 1979.

2. ARAUJO, E.C. Agsistêncla de enfermagem a pacientes externos. Rev. Bras. Enf., Brasilia, $\$ 2(4): 385-395$, out./dez. 1979.

3. ARaUjo, O.M.M. Consulta de enfermagem à gestante. Rov. Bras. Enf., Brasilia, 92(3): 259-270, jul./set. 1979.

4. CASTro, J.B. Estudo exploratórjo sobre a consulta de enfermagem. Rov. Bras. Ent., Rio de Janelro, 28(4):76-94, out./dez. 1975.

5. FRIMM, C.C. Conceito e etlopatogênese da hipertensão arterial. Rev. Bras. Med. Cardfol,, Rio de Janeiro, 4(ed. especial):7-18, set. 1985.

6. GIORGI, D.M.A. et alif. Aderência ao tratamento em hipertensão arterial: influencla de varlávejs estruturals e de estratégias que visem sua melhora. Bev. Bras. Med. Cardiol., 4(4) :167-176, ago. 1985 .

7. HAZOFF, R.G.J. \& CUNHA, L.A.P. Fundo de olho na hipertensão arterial. Rev. Bras. Med. Cardiol., Săo Paulo, s(3):141-144, jul. 1984.

8. IIORTA, W. de A. A metodologla do processo de enfermagem. Rov. Bras. Enf., Rio de Janeiro, 24(6):81-95, out./dez. 1971.

9. LIMA, J.J. \& Silva, H.B. Avaliaçăo clínica de hipertensão. Rev. Bras. Med. Cardiol., São Paulo, 4(ed. especial) :33-35, set. 1985.

10. MION, D.J. et alli. Avaliação clínica-laboratorial em hipertensto arterial. Rev. Bras. Med. Cardiol., Săo Paulo, 3(3):131-140, jul. 1984.

11. PIERIN, A.M.G. A pessoa com hipertensăo em tratamento no ambulatórlo. Săo Paulo, 1985. 109p. (Dlssertaç̆o de Mestrado - Escola de Enfermagem da USP).

12. PIERIN, A.M.G. et alii. Atendimento de enfermagem ao paciente com hipertensăo arterial. Bev. Brag. Med. Cardiol. Săo Paulo, 3(4):209-211, ago. 1984.

13. Silva, H.B. Editorial. Rev, Bras. Med. Cardiol., Săo Paulo, 3(3):113, jul. 1984.

14. SANTOS, B.R.L. Programa de assistencia de enfermagem a clientes portadores de danos cardlovasculares, no ambulatórlo de um hospital geral de ensino de Porto Alegre. Rov. Bras. Enf., Brasilla, 36(3/4):274-281, jul./dez. 1983.

Recebtdo para publlcaço em 26-11-86.

Aprovado para publlcação em 31-6-88. 


\section{ANEXO I \\ HISTORICO DE ENFERMAGEM, LEVANTAMENTO DE PROBLFMAS E PLAANO ASSISTERNCIAL}

HC. FMUSP

INCOR - DIVISAO DE ENFERMAGEM

NOME:

IDADE:

OCUPAÇAO:

PROCEDENCLA:

QUEMXAS PRINCIPAIS: INSTRUÇAO:
HISTORICO DE ENFERMAGEM RG:

No FILHOS:
EST. CIVIL:

DIAGNOSTIOO:

\section{AMBIENTE, HABITOS E MANUTENÇAO DA SAUDE:}

Moradia:

Sono e repouso:

Culdado Corporal:

Condiçōes para o Auto-Cuidado:
Alergias:

Recursos de saúde utilizados:

Medicaç⿸es:

\section{Atividades de lazer e práticas esportivas:}

Hábitos de Fumo:

Etilismo:

Drogas:

AVALIAÇAO DAS FUNÇOES FISIOLOGICAS:

Circulatório Pulso: FC: PA:

Respiratório RF:

Gastrointestinal Nutrição: Peso:

Altura:

Eliminação Intestinal:

Urinário:

Reprodutor:

ASPECTOS PSICO-SOCTAIS:

Expectativas:

Situaçăo relacionada ao emprego:

Interesses sobre a saude-doenç:

DATA:

INFORMANTE:

EMNFERMEMIRA:

COREIN: 


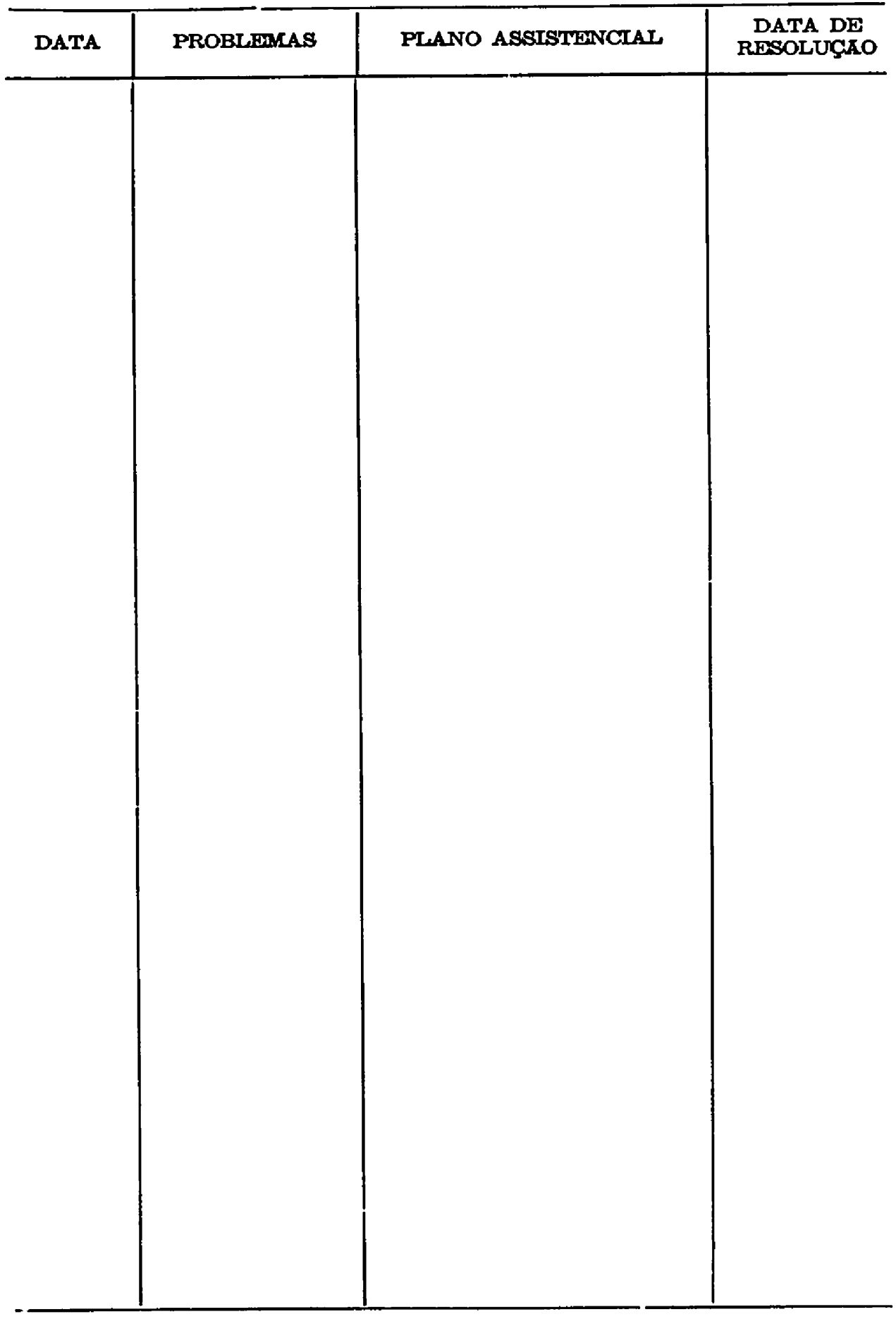




\section{ANEXO II}

CONSULTA DE ENFERMAGEM *

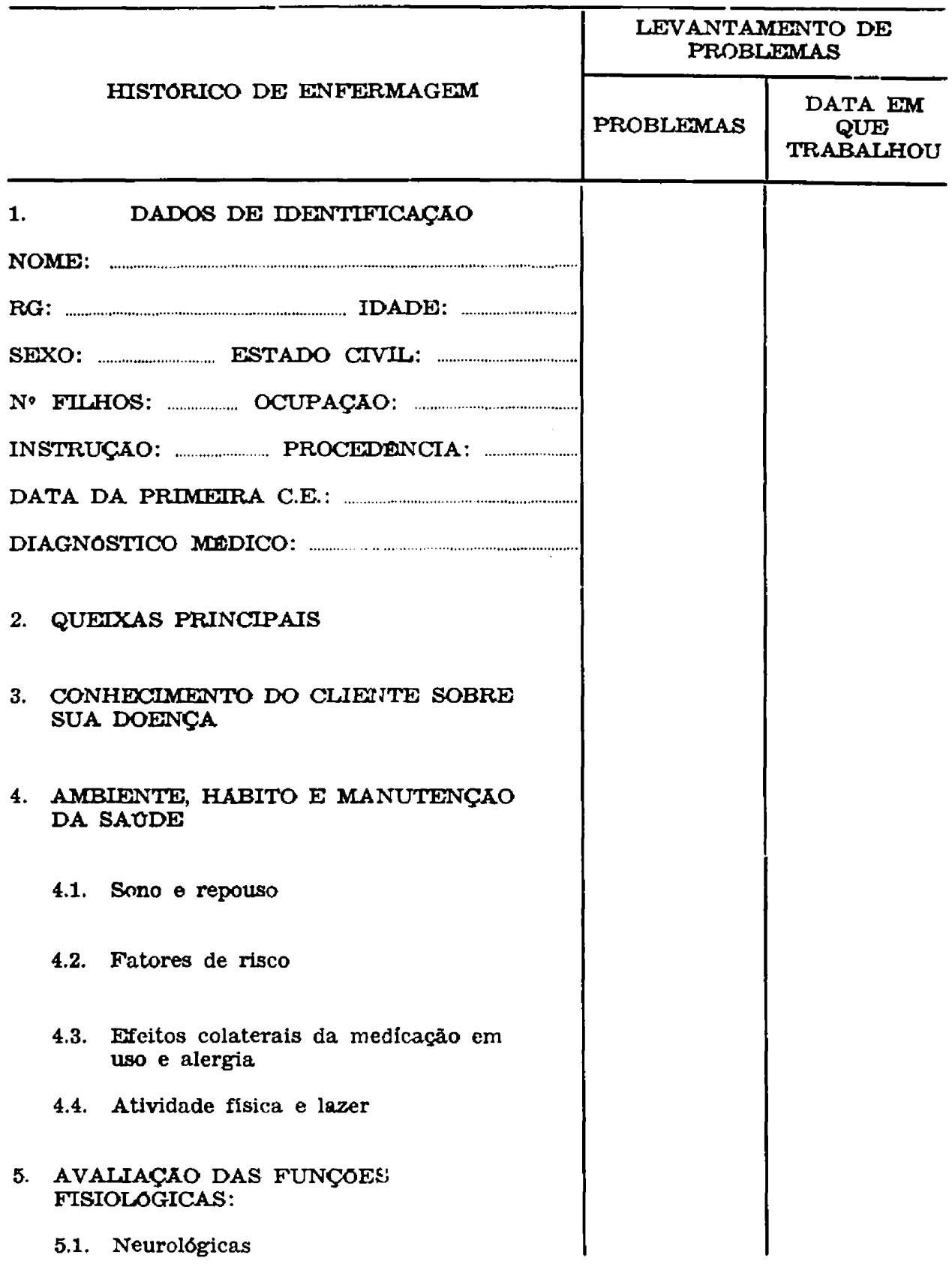

* Instrumento proposto pelas autoras. 


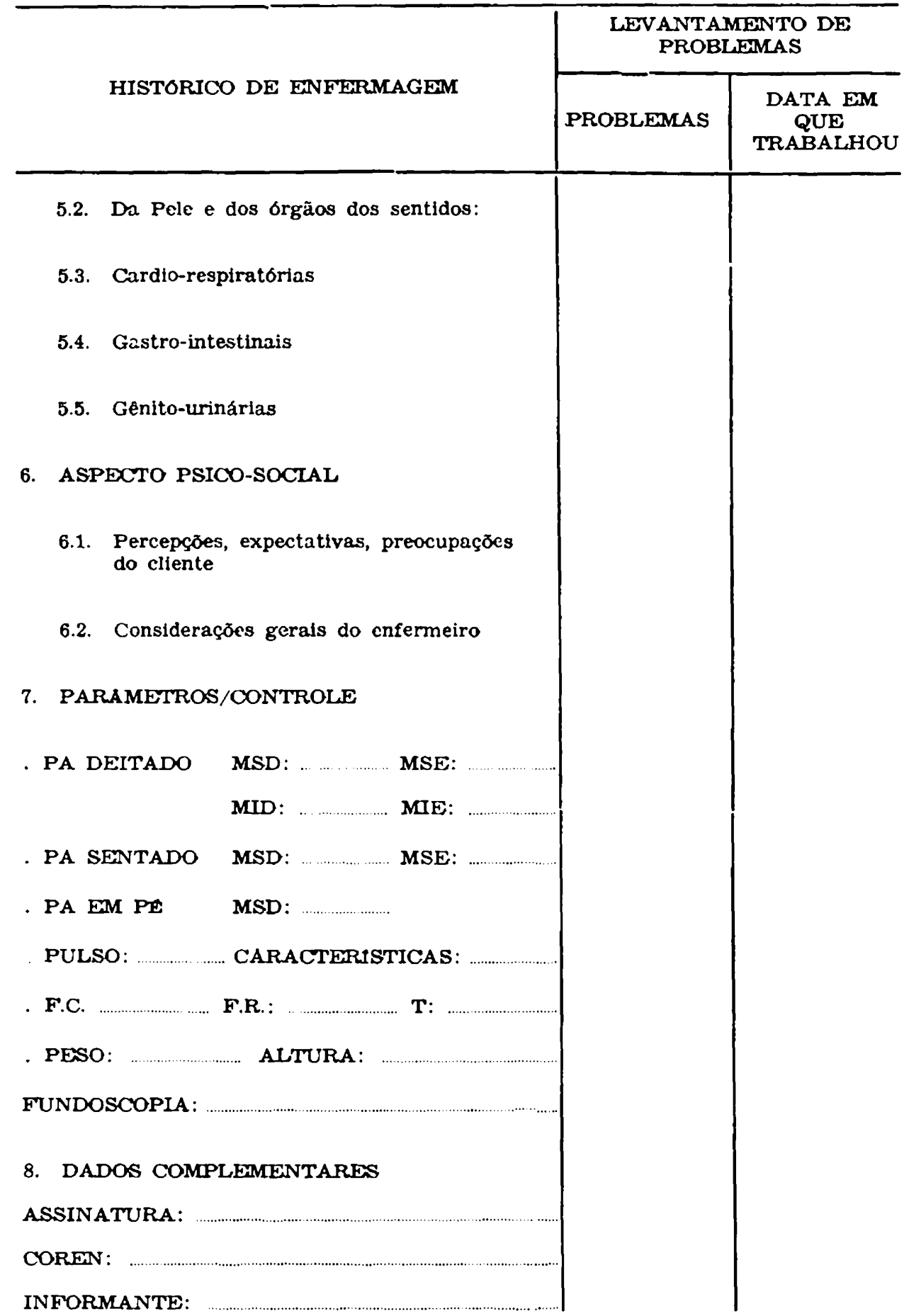

INFORMANTE: 
EVOLUĢAO DE ENFERMAGEM

NOME:

RG:

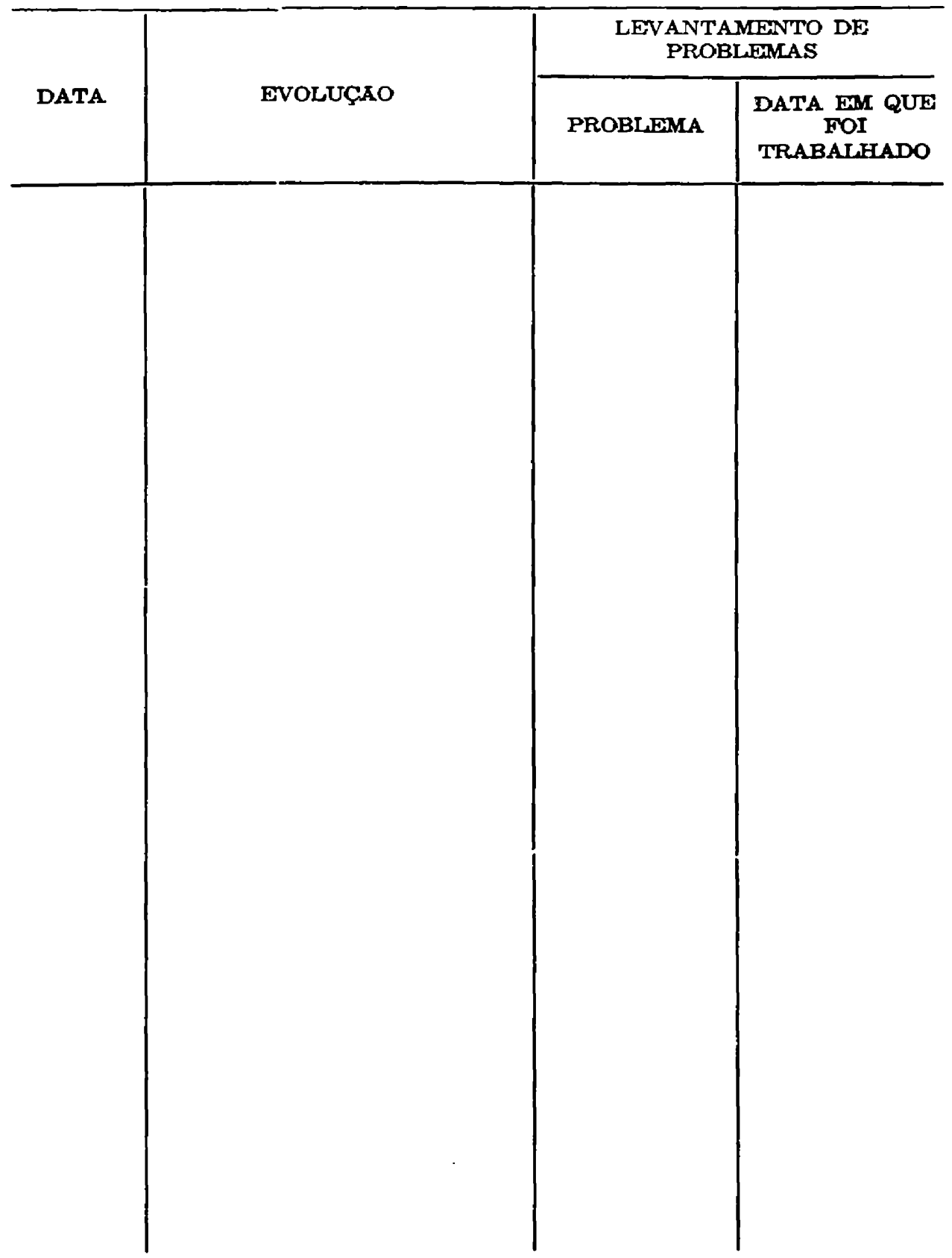

Ret. Esc. Enf. U\&P, Sto Paulo, $22(1): 86-102$, abr. 1988

95 
PLANO DE ORIENTAÇAO E CUIDADOS DE ENFERMAGEM

NOME DO CLIENTE:

ENFERMETRO:

COREN:

OLTIMA VERIFICAÇAO DE PRESSAO ARTERIAL EM MSD:

PESO: Altura

1. MEDICAÇÃ

ORIENTAÇOES E CUIDADOS DE ENFERMAGEM

3. DIETA

2. EXAMES; SOLICTTADOS 


\section{APENDICE}

\section{MANUAL DE ORIENTAGós PARA A CONSULTA DE ENFERMAgeM *}

\section{FINALIDADE}

Este manual, elaborado para a orientação da Consulta de Enfermagem (C.E.) ao hipertenso, tem por finalidade fornecer subsicio ao enfermeiro consultante para exercer essa atividade de maneira sistematizada e uniforme.

\section{CONSIDERACOES BASICAS QUANTO A CONSULTA DE ENFERMAGEM}

\subsection{Definigáo de Consulta de Finfermagem ao hipertenso}

uma atividado sistematizada, privativa do enfermeiro, com utilização de um instrumento próprio e um conjunto de normas e técnicas que visam a promocão do auto-cuidado do cllente hipertenso através do seguimento e ensino continuado.

\subsection{Objetivo}

Assistir e controlar o cliente portador de doença hipertensiva por meio de:

- orientação para o auto-cuidado;

- controle dos fatores de risco;

- detecção de problemas associados;

- manutenção da aderência ao tratamento.

\subsection{Pre-requisitos para a realizacáo ua Consulta de Enfermagem}

- Execução por profissional habilitado: o enfermeiro que desenvolve esta atjvidade deve aprimorar os conhecimentos especificos da patologia e do tratamento, bem como dominar a prática da metodologia proposta.

- Utilização de instrumento específico: deve este ser adequado aos objetivos da C.E., ser sistematizado e dirigido, de modo a levantor problemas caracteristicos da clientela, sem prejuizo do caráter individual da C.E.

\subsection{Programagito do atendimento ao hipertenso **}

- População: clientes com hipertensão leve ou moderada, medicação ajustađa, pressão arterial controlada e retorno à consulta médica marcada para 6 a 12 meses depois, encaminhados pelo serviço médico do programa.

A partir da primeira C.E., serão considcrados clientes de Enfermagem e consequentemente inscritos no seu programa de Hipertensão.

Diariamente serão feitas duas primeiras C.E. no perfodo escolhido.

- Agendamento. Os clientes que atendam aos critérios de inscrição no Programa, apos o atendimento serão encaminhados para marcação do retorno para C.E., no SAME, em código próprio; o agendamento será feito pelo enfermeiro, levados em consideraçáo a avaliação das necessidades do cliente e seus recursos para retorno ao ambulatório.

* Proposta das autoras.

** Baseada no esquema proposto pelo Programa de Atendimento ao cliente hipertenso do INCOR. 
Seráo agendados o retorno de dois clientes por dia no periodo escolhido.

- Receita de medicamentos será dada pelo médico.

- Requisição de exames laboratoriais e complementares serão pedidos periorlicamente pelo médico.

- Encaminhamento para psicólogo, nutrícionista, assistente social e fisioterupeuta será felto pelo enfermeiro; e para odontólogo e médicas de outras especialidades, pelo médico.

Após o término da avaliação do cliente pelo enfermeiro, o atendente levará ao médico a folha de evolução de enfcrmagem para os procedimentos médicos de rotina tais como manutenção de receita e pedido de exames laboratoriais ou complementares.

Em casas especiais de alteraçães minimas e transitórias da condiçăo do cliente, que exigem mudança de tratamento, o enfermeiro deverá dialogar com o médico sobre as possivels alteraçoes de medicação e/ou encaminhamento aos profissionais acima citados.

- Retorno a consulta médica. Durante a C.E., se forem detectados sinais de descompensaçăo do cliente, o enformeiro procisará ser capaz de avaliar năo 86 qual a assisténcia de enfermagem indicada, como também se o mesmo necessita de avaliação médica para conduta e tratamento especifico, podendo faze-lo retornar ao serviço médico.

\section{NORMAS PARA O PREENCHIMENTO DO INSTRUMENTO PRECONIZADO}

\subsection{Principlos a serem coasiderados}

- Histórico de Enfermagem. Deve ser:

- de competencia exclusiva do enfermeiro;

- assinado pelo enfermeiro e conter o número de sua inscriçăo no COREN;

- preenchido na primeira consulta de enfermagem, sendo investigados e anotados todos os itens em profundidade;

- preenchido com um traço o espaço destinado a resposta do cliente, no caso de năo existéncia de respasta;

- preenchido na totalidade de seus itens;

- arquivado no prontuário do cliente imediatamente após seu preenchimento.

- Levantamento de Problemas. Deve ser:

- de competencia exclusiva do enformeiro;

- assinado por este e conter o número de sua inscriçăo no COREN;

- atividade pasterior ao histórico de enfermagem na primeira consulta de enfermagem, ou à evolução, nos retornos;

- relativo a todos os problemas encontrados no histórico de enfermagem ou na evolução;

- problemas anotados na coluna pertinente, paralelamente ao dado investigado;

- anotada no espaço «data em que trabalhou», a data em que o enfermetro realizou uma açăo especifica; lhados.

- retomados, nas retornos do cliente, os problemas levantados o nåo traba- 
- PIano de Orientaçăo e Cuidados de Enfermagem. Devem ser:

- da competência exclusiva do enfermeiro;

- assinado pelo enfermeiro e conter o número de sua inscrição no COREN;

- feito em duas vias, sendo a primeira fornccida ao cliente e a segunda arquivada no seu prontuario; cliente;

- acrescentados na 1* coluna, a seguir a kdieta», os problemas individuais do

omitidos, na 1* coluna, termos que possam influir negativamente no estado psicoemocional do cliente;

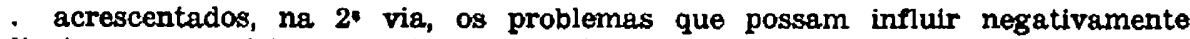
no cliente, para registro e controle do enfermeiro;

- referidos, na $2^{*}$ coluna, a orientaçáo dada ao cliente e os cuidados de enfermagem, a ele prestados, sempre com uso de verbos no infinitivo, redigidos com clareza o objetividade evitando o emprego de termos técnicos e determinando horario, se necessário.

- avaliado, no retorno, o plano anterior e o levantamento de problemas, reformulando e reforçando orientaçăo e cuidados bem como acrescentando e trabalhando novas problemas;

- inutilizados os espacos em branco após o término do preenchimento;

- orientado o cliente quanto à data do próximo retorno.

- Evoluçắo de Enfermagem. Deve ser:

- de competencla exclusiva do enfermeiro;

- assinado pelo enfermeiro e conter o número de sua inscriçăo no COREN;

- feito em todo o retorno do cliente;

- arquivado no prontuário do cliento logo após sua elaboraçấ;

- de caráter evolutivo.

3.2. Rotelro de orlentagá para o preenchimento do instrumento preconizado

\section{HISTORICO DE ENF'ERMAGEM}

\section{DADOS DE IDENTIFTCACAO}

- preencher todos os dados solicitados.

\section{2. quHXas pRINCIPaIs}

- investigar as queixas que o cliente refere desde a sua ultima consulta e estar alerta sobre:

- cefaleia, epistaxe, tontura, lipotímia, síncope, distúrbios visuais, formigamento e parestesia, edema, dor em membros inferiores, cansaço, dispnéla, precordialgła e palpitaçóes.

\section{CONGHCTMENTO DO GLENTE SOBRE SUA DOENCA}

- tempo de duraçăo dos sintomas principais: 
- há quanto tempo é ciente de sua h:pertensão.

- se está adaptado às mudanças de hábito de vida causadas pela doença.

- se o tratamento lhe traz algum problema financeiro.

- se tem conhecimento de outras doenças: diabetes, doença arterial coronariana, insuficiência cardiaca congestivi, nefropatias, dislipidemias, doença vascular periférica, acidente vascular cerebral.

\section{AMBIENTE, HABITO E MANUTENÇAO DA SAODE}

\subsection{Sono o Repoisso}

- qualidade de sono, uso de drogas.

- duraçáo.

- regularidade, horário.

- se repousa, como o faz, frequiencia $\theta$ horário.

- situações decorrentes da medicação.

\subsection{Fatores de Risco}

- alimentaçăo - apetite, intolerância

- tipo de alimentação, histórico alimentar, com horários.

- controle do sal, como é feito?

- obesidade - obeso?

- controlada? como controla?

— não controlada.

- «stress» - situações diversas, principalmente de ambiente, trabalho, familia.

- auto-medicação - medicaçães sem prescrição médica.

- aderência ao tratamento prescrito - como faz o tratamento.

- tabagismo - fumante, quanto furra e há quanto tempo foi fumante, fumou por quanto tempo e quando deixou o hábito.

- álcool - quantificaçăo e o tipo.

- uso de corticóides e de anticoncepcional.

. diabetes, dislipidemias.

\subsection{Efeitos colaterals da medicação em uso $\theta$ alerglas}

- quais as medicaçōes em uso e seus efcitos colaterais.

- a que drogas que é alérgico e o tipo de alergia.

\subsection{Atividade física e lazer}

- vida sedentária.

- dificuldades no trajeto de rotina (ladeira, escada).

- se pratica algum esporte ou exercicio (tipo e periodicidace).

- lazer (tipo e periodicidade). 


\section{AVALIACAO DAS FUNCOES FISIOLOGICAS}

\subsection{Neurológicas}

- orientação auto e alopsiquica.

- paralisias, parestesias, formigamento e caracteristicas, convulsão - frequência, medicaçăo em uso.

- cefaléia - Intonsidade, localização e frequência.

\subsection{Da pele e dos órgáos dos sentidos}

- coloração de mucosas.

- turgor e integridade da pele.

- acuidade dos 6rgãos dos sentidos.

\subsection{Cárilo-Respiratórlas}

- precordia'gla - frequencia, intensidade, duração, tipo, localizaçăo, relaçáo com algum fator.

- palpitaçбes - frequencia, tipo, relação com algum fator.

- perfusto periférica - condiçōes.

- estase jugular - turgor e condiçóes de aparecimento.

- edemas - local, Intensidade, frequência, sinal de Godet.

- dispnéla - frequência, intensidade, tipo, relaçăo com algum fator.

- cansaço - frequencia, intensidade, tipo, relação com algum fator. dor torácica - frequência, intensidade, tipo, relaçåo com algum fator.

- tosse - seca, produtiva, característica da secreção, intensidade.

- cianose - intensidade, local.

\subsection{Gastro-intestinais}

- hábito intestinal - frequencia da evacuaçăo, aspecto das fezes, incontinência, dor, desconforto.

- desconforto géstrico - caracteristicas.

- Intolerancia medicamentosa - especificar qual medicamento.

\subsection{Genito-urinárias}

- Sistema urinário - frequência das micçós, incontinência, nictúria, disúria, anúria, oligúria, polaciúria, investigar em quais situaçðes.

- Sistema reprodutor - atividade sexual, presença de serreçðes e pruridos; em mulheres: menopausa, tipo de contraceptivo, intercorrencias obstétricas, colposcopla.

\section{ASPECTOS PSICOSSOCIAIS}

6.1. Percepcōes, expectativas, preocupaçoes do cliente

6.2. Consideracões gerals do enfermelro sobre o cliento

- percepçăo do enfermeiro sobre o clicnte, aceitaçăo da consulta, nivel de entendimento do cliente, caracteristicas pessoais e receptividade. 


\section{PARAMETROS/CONTROLES}

- PA - deitado: nos 4 membros.

- sentado: nos membros superiores.

- em pé: no membro st:perior direito.

Depende dos niveis tensionais apresentados pelo cliente. Deve ser verificadia em ambiente tranquilo e com fita de correção.

- PULSO - contar pulso radial ou carotídeo e anotar.

- observar a presença e as caracterfsticas de pulso pecioso, tibial popliteo, radial, umeral, anotar alteraçzes.

- FC - contar e anotar pulso apical.

- FR - contar e anotar.

- T - verificar e anotar temperatura axilar.

. PESO - pesar o cliente e anotar.

- AltURA - medir o cliente e anotar.

- FUNDOSCOPLA - a ser feita na primeira C.E. para servir de parâmetro para constataçäo de alteraços posteriores.

- caracteristicas: estreitamento de artérias retinianas, hemorragias retinianas, exsudatos com ou sem papiledema retinianas.

\section{DADOS COMPLEMUNTARES}

- Levantamento de prontuário

- tratamento medicamentoso; última receita médica.

- dados laboratoriais recentes (s6́dio, potássio, glicemia, colesterol, triglicérides, urina I).

- atendimento por outros profissionais. 